\title{
Investigation of geophysical challenges in land seismic data acquisition in Nigeria: case study of parts of the Niger Delta region
}

\author{
C. N. Onwubuariri ${ }^{1}$ L. S. Al-Naimi ${ }^{2}$ - B. I. Ijeh $^{1} \cdot$ T. I. Mgbeojedo $^{3} \cdot$ M. U. Igboekwe ${ }^{1} \cdot$ L. A. Nnanna ${ }^{1}$
}

Received: 23 April 2020 / Accepted: 19 November 2020 / Published online: 12 January 2021

(c) The Author(s) 2021

\begin{abstract}
Geophysical analysis was carried out to evaluate the challenges encountered in land seismic exploration within the study area. This analysis cuts across various stages in land seismic acquisition. These stages include the following: the availability of the prospect map as originally planned by the prospect owners - the client, the desk study and planning of this map by the seismology section (planning seismologist) for acquisition convenience and the field implementation of the acquisition which the survey, drill and recording (preloading, shooting, swath move, line check, LAUX crew and recording platform) sections carried out. The challenges observed included environmental challenges, noise interference, weather conditions (statics or electrostatics interference), line break, faulty equipment, wrong detailing, cake or expired explosives, poor or compromised supervision, security and permit challenges. These challenges are peculiar to Nigeria due to inadequate implementation of policies that guide human settlements and activities. Nigeria is within the climate region where most at times it is very impossible to control natural events like cloudy weather, rainfall, thundering and lightening. As such, the problem of static charges interfering with acquired seismic data becomes inevitable, mostly during the rainy season. Almost total dependency on imported technology and lack of readily available experienced manpower also contribute to these challenges, most especially when it has to do with proper inspection of equipment and materials required for the acquisition and supervision processes. Approaches to follow to minimize the observed challenges were equally highlighted.
\end{abstract}

Keywords Seismic data acquisition $\cdot$ Niger Delta $\cdot$ Geophysical challenges $\cdot$ Line break $\cdot$ Interference $\cdot$ Nigeria

\section{Introduction}

In seismic data acquisition programme, careful and welllaid-out plans before the field operations kick off are needed for it to be successful. In this case, a pre-plot is provided for acquisition planning and development. For acquisition convenience, the pre-plot is divided into swaths by a planning seismologist.

This pre-plot which also contains the location and geometry of the design is superimposed on the map of the area for acquisition. This helps in aligning shot points on their

T. I. Mgbeojedo

toomgbeojedo@gmail.com

1 Department of Physics, Michael Okpara University of Agriculture, Umudike, Umuahia, Nigeria

2 Department of Chemistry and Earth Sciences, Qatar University, Doha, Qatar

3 Arab Center for Engineering Studies, Doha, Qatar actual location on the earth's surface. This properly guides the planner on movement of unsafe points with respect to non-seismic objects (NSOs) while monitoring the fold as specified. Carrying out seismic line establishment and cutting by the survey section can then be done using Global Positioning System (GPS), for actual location of shot points within the prospect of acquisition by the survey crew.

This is followed by survey line check by quality control officers who ensure that the map statement coincides with the reality on ground as established by survey crews and as well report any disparity observed with respect to shot points and NSOs, stating the exert position, bearing and distance of the NSOs with respect to the shot points on a report form for the planning seismologist to work with. This report is vital as there are various specified safe shooting distances set by the Department of Petroleum Resources (DPR) and other companies for different NSOs to reduce to the barest minimum the negative environmental impact of detonated shots and as well avert unnecessary damage. With all these quality checks being carried out, the drill and preloading




crews are set to move into the source lines (cross lines) for the commencement of data acquisition.

Prior to the field operations, permitting is carried out by the community affairs section of the acquisition company, most at times in conjunction with the client company. It is a common knowledge that the survey area belongs to individuals, corporate organizations, government or religious bodies. Therefore, before seismic acquisition process could commence, it is of necessity to get the right of way from the owners. This assignment is handled by a permit agent.

The maps developed by the planning seismologist during the initial planning stage show where these properties are located. Therefore, the permit man ascertains who owns these properties. In land operations in Nigeria, the traditional rulers are the best source of information for property owners. The complications that arise in many parts of USA where a piece of land has two owners, one owning the surface and another the subsurface, do not arise in Nigeria as the owner of the surface also owns the subsurface and has the mineral right. This situation makes the work of the permit man easier as he is concerned with contacting just one owner. With these steps, seismic acquisition work is set to be carried out.

\section{Location and physiography}

The study area is located within the upland parts of Bayelsa State which includes the following local government areas-Yenegoa, Ekeremor, Kolokuma/Opokuma, Ogbia and Sagbama which covers an area of approximately 5927 square kilometres. These areas lie between longitude $6.0699^{\circ} \mathrm{E}$ and latitude $4.7719^{\circ} \mathrm{N}$ with an average elevation of about $10.3632 \mathrm{~m}$ (34 ft) above sea level. Figure 1 shows the map of Bayelsa.

\section{Geology of the area}

The Niger Delta is situated on the West African continental margin at the apex of the Gulf of Guinea, which formed the site of a triple junction during continental break-up in the Cretaceous. It extends throughout the Niger Delta Province as described by Klett et al (1997). From the Eocene to the present, the delta has prograded towards the southwest, forming depobelts representing the most active portion of the delta (Doust and Omatsola 1990). These depobelts form one of the largest regressive deltas in the world with an area of some $300,000 \mathrm{~km}^{2}$ (Kulke, 1995), a sediment volume of $500,000 \mathrm{~km}^{3}$ (Hospers, 1965), and a sediment thickness of over $10 \mathrm{~km}$ in the basin depocentre (Kaplan et al. 1994). The delta sequence comprises an upward-coarsening regressive association of Tertiary clastics up to $12 \mathrm{~km}$ thick (Doust and Omatsola 1990). It is divided into three lithostratigraphic units which include:

(i) Marine claystones and shales of about $6.5 \mathrm{~km}$ thick at the base (Akata formation);

(ii) Alternations of sandstones, siltstones and claystones of about $3.5 \mathrm{~km}$ thick (Agbada formation); and.

(iii) Alluvial sands of about $2 \mathrm{~km}$ thick at the top (Benin formation) (Doust and Omatsola 1990; Agoha et al. 2015).
Fig. 1 The location map of Bayelsa State (after Warebi and Tonye 2018)

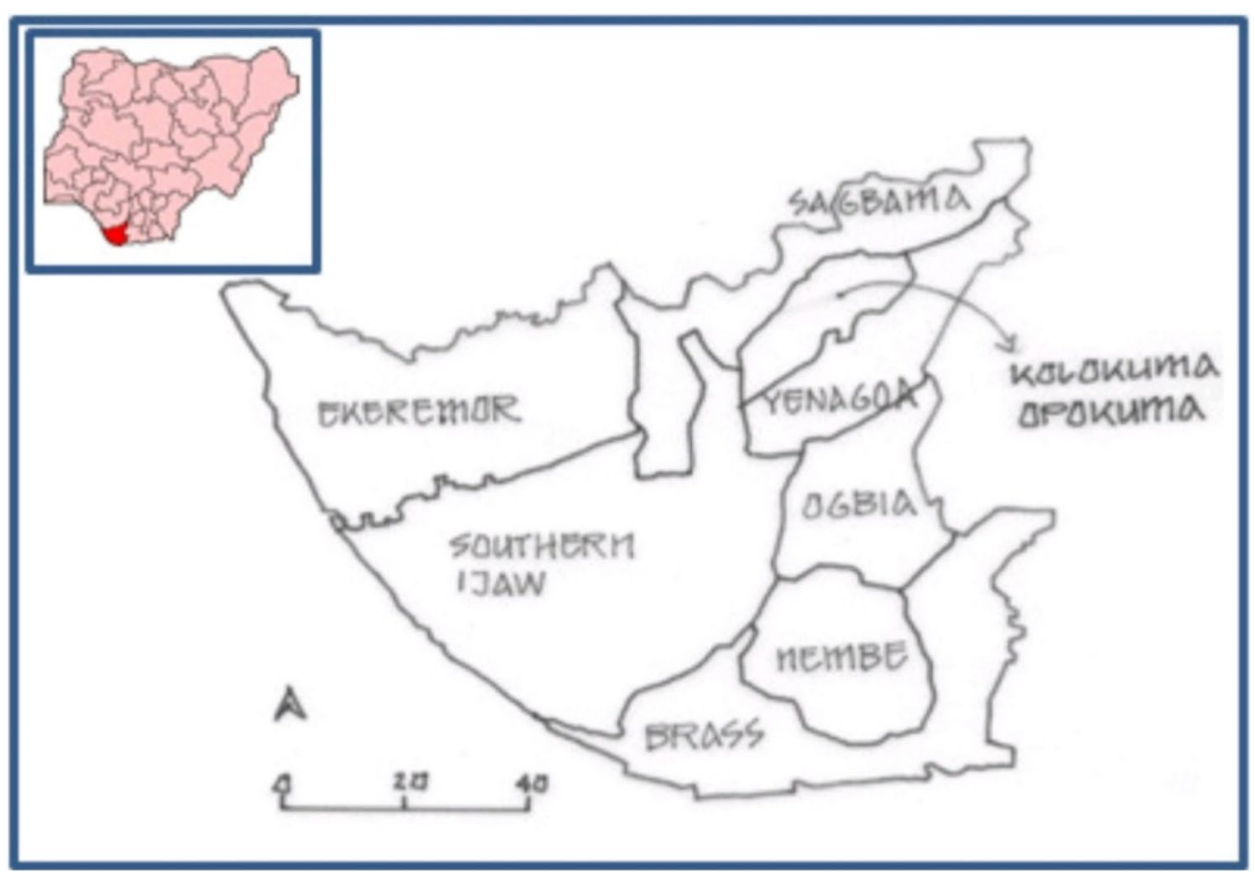


The Benin Formation, on which the study area sits, consists of predominantly massive, highly porous, fresh waterbearing sandstone, with local interbeds of shale. It is a continental deposit of Miocene to Recent age (Ejedawe 1981; Weber and Daukoru 1975).

Major growth-fault trends cross the Delta from northwest to southeast, dividing it into a number of structural and stratigraphic belts, called depobelts, which become younger towards the south. Hydrocarbons have been located in all of the depobelts of the Niger Delta, in good-quality sandstone reservoirs belonging to the main deltaic sequence (Doust 1990).

\section{Materials and method}

The prospect map of the study area was divided in seven swaths for acquisition convenience. Apart from the seismology department which oversees the seismic operation, other sections are involved in field establishment of the planned prospect and data acquisition. These sections include:

\section{Survey section}

The primary goal of the survey section of any seismic crew is to establish seismic lines for drilling of shot points by drillers. Prior to the establishment and cutting of source and receiver lines, equipment and instruments are calibrated to client's specifications for accuracy. The following processes were adopted for the achievement of this purpose:

a. A base map strictly obeying the predefined coordinate boundaries of the prospect area was produced by surveyors based on client's specifications.

b. GPS points were established (GPS Network/GPS monumentation) in the prospect area which provided guides within the prospect area as they establish and cut the source and receiver lines. These GPS points were named based on codes given by the client, but in a situation where none is given, the acquisition contractor assigns codes to GPS points suitable for the project. These GPS points are called primary controls.

c. Control lines were designed and marked out on the map. This helped in guiding the surveyors in the field as they cut seismic lines from a known point to another known point (ties). Control lines are called secondary controls.

d. The prospect was systematically divided into swaths as specified by the client or the planning seismologist. In this study, there were seven swaths and each swath is made up of seven receiver lines. With these conditions being met, cutting of lines commenced.

e. Shot points established on cut source lines were marked using red or yellow ribbon as the case may be and they were named according to its source line number and receiver line number $(\mathrm{X} / \mathrm{Y})$, while receiver stations were marked with a blue ribbon and named using its receiver line number and source line number $(\mathrm{Y} / \mathrm{X})$.

f. After line cutting, survey section submitted report on the lines cut to the seismology section.

A swath is just a fraction of the prospect map. In the study area, a swath contains 12 receiver lines. Swath size is not defined. It is subject to the owners of the field to be acquired. Swath is for acquisition convenience. Figures 2, 3 and 4 show swaths obtained in the study.

\section{Field quality control unit}

This unit is a branch of seismology department. They monitor the quality as well as supervise all the field activities from start to finish. Therefore, they are attached to all units during field operations. The quality control officer or field seismologist attached to survey ensures the following during and after survey operations:

a. That the lines are cleanly cut to reduce line hazards

b. That the peg numbering of shot points on source lines and receiver stations on receiver lines are properly done by the surveyors

c. That shot points are safely established from non-seismic objects (NSOs) as specified by the regulatory body; otherwise, they suggest that such affected points be shifted or moved to safer positions.

\section{Drill section}

The drill section is in charge of drilling single deep holes (SDH) for burying of explosives. In the most recent acquisition carried out within the Niger Delta, a semi-automated drilling system is used. Single deep holes (SDH) of mostly $45 \mathrm{~m}$ deep are drilled at shot point positions using the system to bury the source of seismic energy, mostly dynamites. It is regarded as semi-automated method because the drilling process is not completely labour intensive as it also requires the assistance of a mechanized pump. The major equipment used includes water pump, swivel head, drill stems, pipe wrenches, drill clamp, drill bit and drilling mud. This drilling system is used to achieve greater depths of up to $70 \mathrm{~m}$; therefore, it is also employed in acquisition projects for upholes $(66 \mathrm{~m})$. This method of drilling requires two people called turners (as shown in Figs. 5 and 6) to handle and turn the T-shaped clamp during the drilling operations. During drilling, drilling mud is constantly pumped into the hole to bring out the cuttings, flush the holes and as well seal the walls of the drilled SDH to prevent carve-in or collapse. This

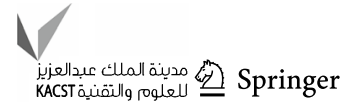




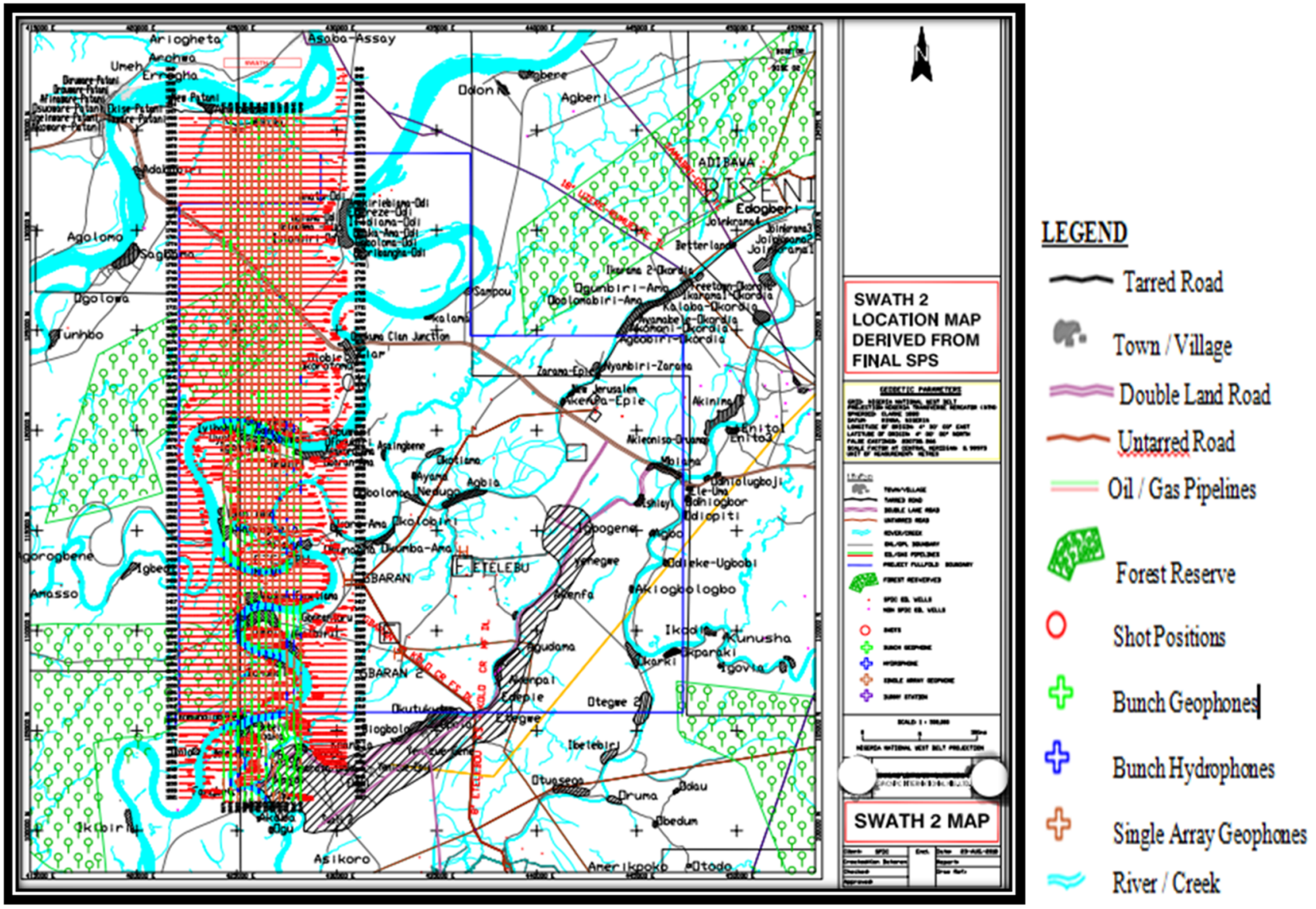

Fig. 2 Swath 2 of the prospect map

cyclic movement of the drilling mud activities is presented in Fig. 5.

\section{The recording section}

This section oversees the preloading, shooting, swath move, line check, LAUX crew and recording platform operations.

\section{Preloading operation}

This involves the burying of explosives by preloaders. The name "pre" implies the first activity that takes place before proper acquisition commences. Only single deep holes (SDHs) are usually preloaded. A detonator of $55 \mathrm{~m}$ lead is usually attached to dynamites while loading it in a single deep hole. For most projects within the region, $2 \mathrm{~kg}$ dynamites are used. The preloaders make use of the loading poles to drop or bury the dynamites inside the subsurface and the preloaders often work with the drill crews to load or bury the dynamites immediately after any SDH of $45 \mathrm{~m}$ is drilled.

\section{Shooting operation}

This involves the shooting crews. The shooters as mostly called, detonate the buried dynamites using the blaster. They carry out this operation by connecting a $75 \mathrm{~m}$ firing line or wire from the blaster to the detonator wire at the surface. A blaster (Fig. 7) is used in charging up the detonator for the explosion of dynamites.

\section{Swath move operation}

Swath movers are in charge of this process. They are also called the cable laying crews. Swath moving operation is ahead of every recording operation as they lay cables and geophones for signal picking and transmission after shots are detonated. Also, after shooting and recording have been concluded for a particular swath, they pick up the cables and geophones. The crew is composed of lots of members for effectiveness. These geophones are shown in Fig. 8a 




Fig. 3 Swath 5 of the prospect map

\section{Field digitizing operation}

The field digitizing unit (FDU) is used to collect all the data from its associate geophone array for a single station, converts them from analog to digital form which the recording instrument at the platform can recognize. Figure $8 \mathrm{~b}$ shows a typical FDU.

\section{The LAUX crew operation}

"LAUX" means line auxiliary unit crossing. The duty of this crew is to connect all receiver lines in a swath to the LAUX or traverse cable. From the transverse, all receiver lines in a swath are connected to the recording platform.
Line check operation

This involves the correction of faults on receiver lines. Line checkers are mainly for line troubleshooting. They majorly make use of a multimetre for checking and testing of battery voltage, geophone, line acquisition unit line (LAUL) and link cables.

\section{The recording platform}

This is where the seismic reflections picked by the receptors (geophones) are recorded. The recording instrument is mounted on the land boogie. Sercel equipments, mostly 


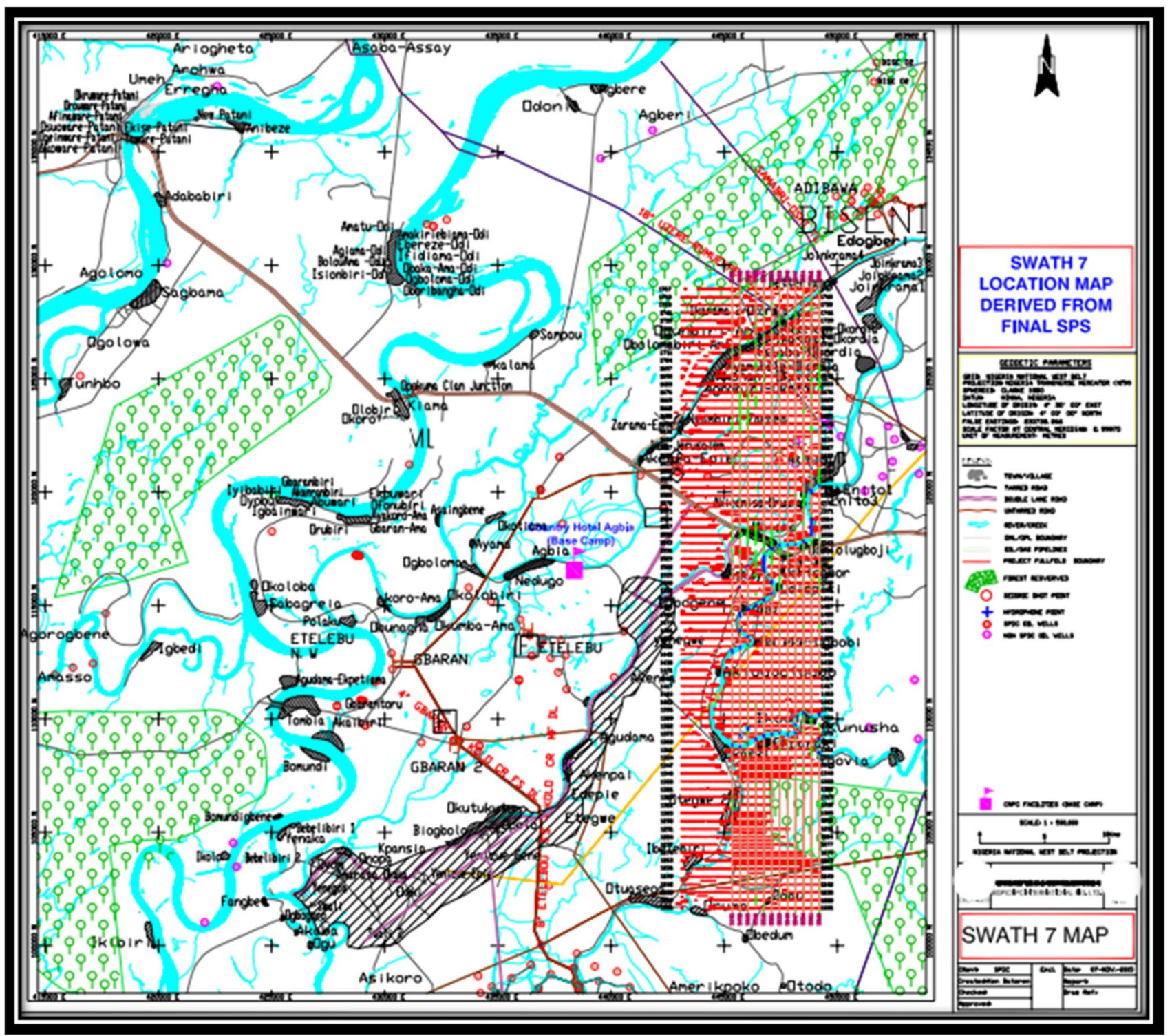

Fig. 4 Swath 7 of the prospect map

SERCEL 408XL or 428XL Telemetry System are used as platform workstations. This arrangement is shown in Fig. 9.

\section{Results and discussion}

\section{Land seismic data acquisition challenges}

In land seismic acquisition in Niger Delta, several limitations are encountered. These limitations hamper effective, efficient and quality data acquisition. These challenges cut across a wide range of factors, which include but not limited to environmental and climatic disturbances, equipment problems, security and permit challenges, etc.

\section{Environmental challenges}

The rate of urbanization in most part of Niger Delta, especially the study area (Bayelsa upland), creates several environmental challenges that affect the data acquisition process. Lots of non-seismic objects like buildings, tarred roads, electrical installations, already existing oil facilities, etc., are possible obstacles to the process. Their presence automatically leads to the removal and most at times killing of shot points which were already in the project or prospect design. These points' removal or movement due to NSOs will influence the anticipated design outcome, by negatively affecting the specified and expected fold of seismic bins to be sampled, thereby causing a fold drop. This in turn will 


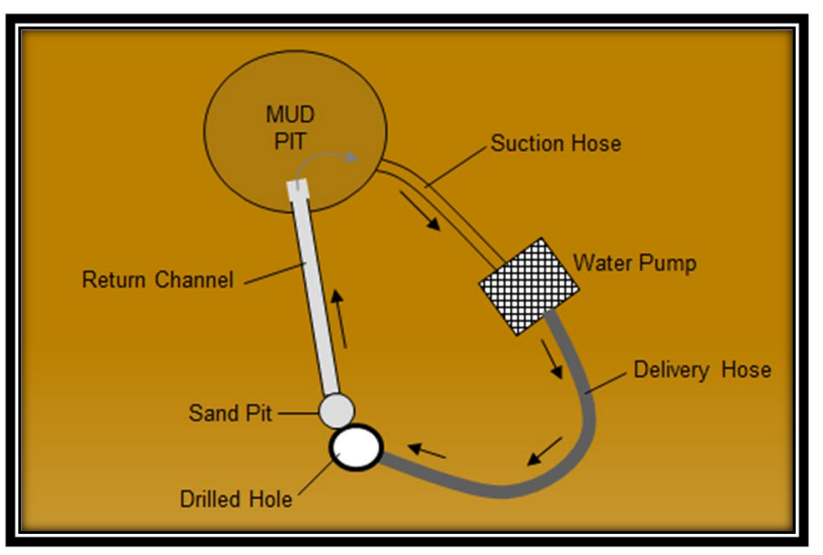

Fig. 5 Cyclic movement of drilling mud (for flushing) in the semiautomated method of drilling

affect the expected result from the prospect, as not all the areas to sampled are investigated.

Another environmental challenge is that of noise. In seismic acquisition, a serene environment is best fit for it. This is to avoid noise interference on the data. These interferences could emanate from various human activities like moving vehicles, lumbering activities, etc. These activities generate seismic signals or waves which are picked by receiver stations close to them alongside the detonated shots. These activities can cause cancelling out of signals, thereby making information on the acquired data too difficult to be extracted or processed.

A raw shot is shown in Fig. 10, while Fig. 11 shows a raw shot affected by interference and environmental noise.

In Fig. 12, a raw shot with noise is given, while Fig. 13 shows the shot after the noise has been attenuated.

\section{Weather condition}

Weather consideration should not be over looked in land seismic data acquisition. Weather plays a vital role in any smooth seismic operation and this cut across both the safety part of the operation and effectiveness of acquisition itself. It is not just humanly unsafe to carry out operations under cloudy or rainy conditions to avoid electrocution and any other accident that may result from it due to lightning and thunder storms because of the materials involved

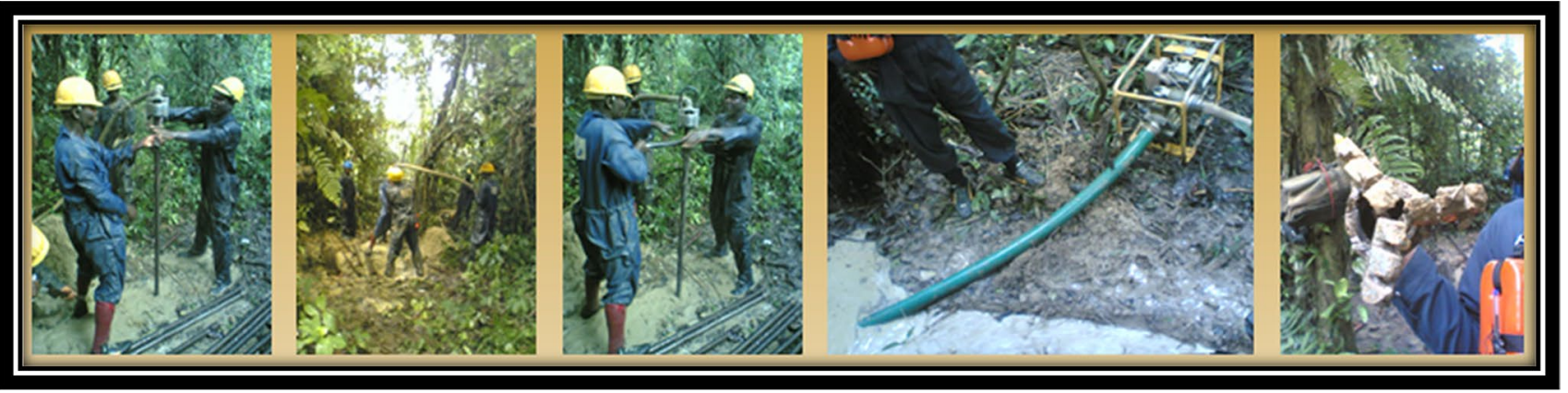

Fig. 6 Turners using a semi-automated drilling system to drill a single deep hole of $45 \mathrm{~m}$

Fig. 7 Blaster

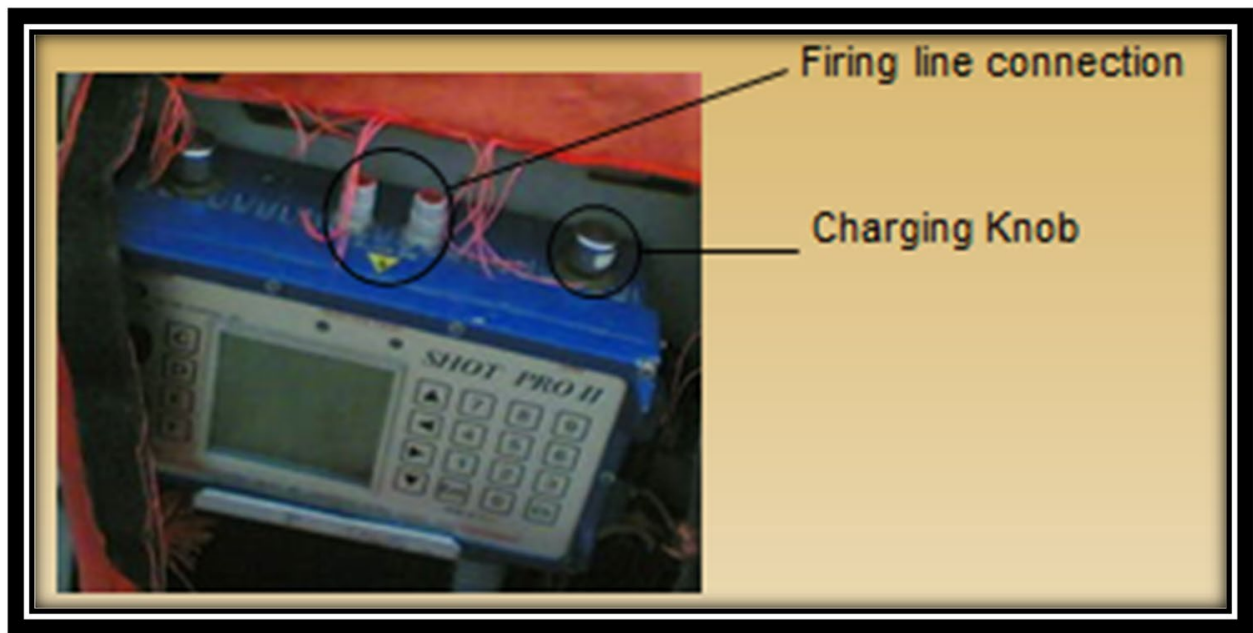



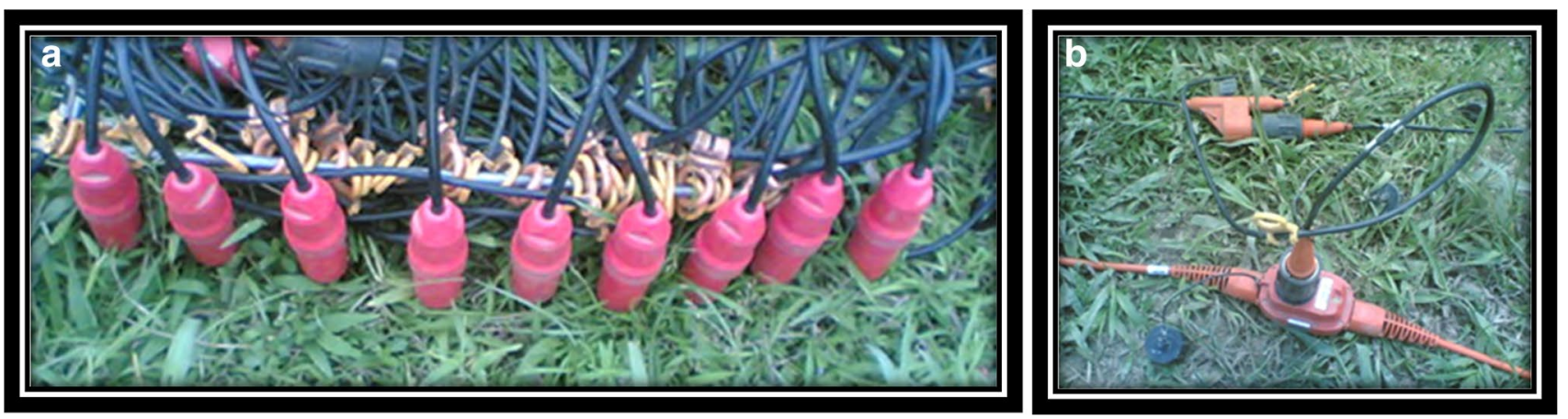

Fig. 8 a Geophone strings and cables. b Field digitizing unit

Fig. 9 The platform and platform activities

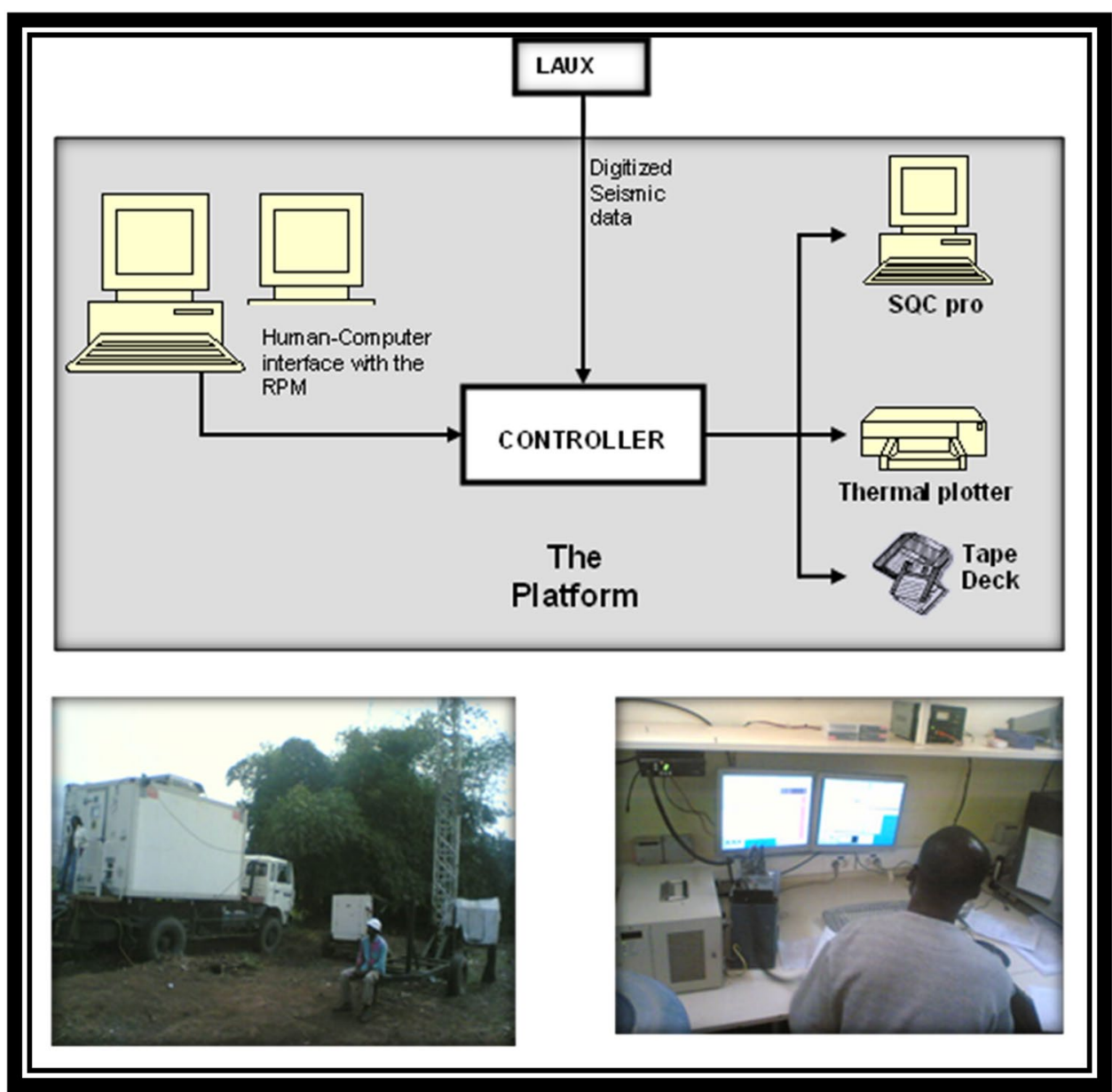

in the operation - dynamites, detonators, engines, metals (loading poles, drill stems), batteries, cables, etc., it is also a risk to the entire operations as it exposes the acquisition equipment to serious damage. This can as well cause distortion and drop in the quality of data acquired. Bad weather can give rise to the following:

\section{Statics or electrostatics interference}

In this case, the transmitted signal from the point of generation-shot points, which is converted to electromagnetic wave and transmitted to the observer's platform for storage is interfered by charges in the atmosphere, thereby corrupting 


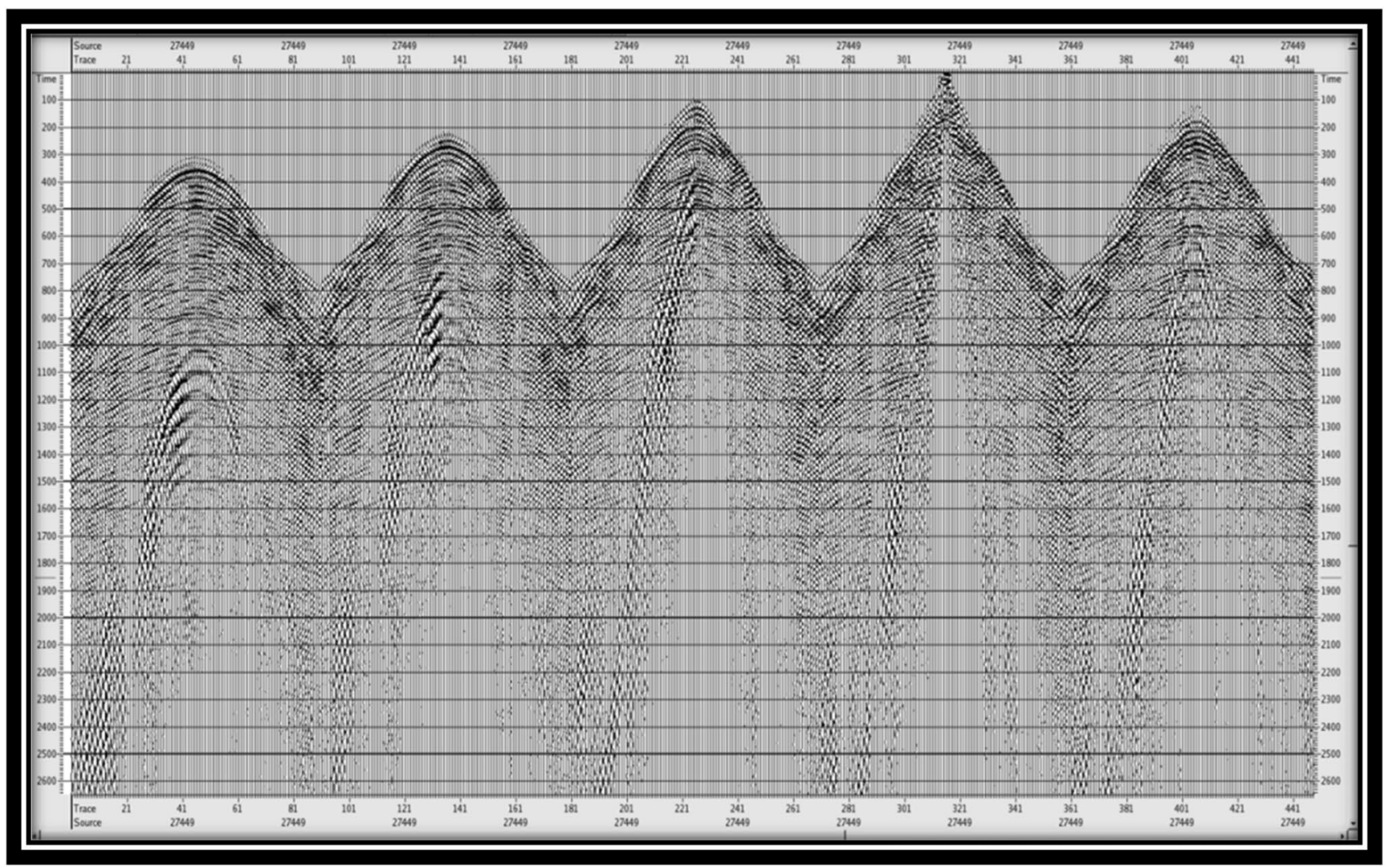

Fig. 10 Raw shot unaffected by noise

the transmitted signals by assigning a different signature to them.

\section{Line break}

Charges in the atmosphere can as well cause a discontinuity or break within interval of seismic signature (Fig. 14). This is observed when acquired shots are viewed on the screen or printed out. These breaks or discontinuities will cause loss of vital information from the acquired shot within the time frame it occurred.

\section{Faulty equipment}

Seismic data acquisition would have been a difficult activity and very impossible to achieve if there are no equipment aiding the process. These equipments have functionalities and also a pattern which they operate. The study of these equipment and their functions are paramount to avert equipment malfunctioning which could lead to faulty or wrong signal generation. Calibrating the equipment to the clients' specification and constant servicing and maintenance reduces the risk of equipment breakdown and errors due to faulty equipment. Faulty or damaged equipment could cause the following problems:

\section{Line break}

Apart from statics charges, faulty or damaged material like cut cables on receiver lines can give rise to discontinuity or breaks in acquired data. Faulty and improperly pinned geophones could also give rise to line breaks.

\section{Cut charge}

This is often experienced during preloading process. A preloader may subconsciously cut the detonator or cap lead with the basket of the loading pole while burying the explosives inside the SDH drilled.

\section{Wrong detailing}

Wrong detailing or misinformation between the field and the platform can cause a serious challenge in acquisition. This challenge often noticed during data processing as a result of wrong detailing is called wrong geometry.

\section{Wrong geometry}

Wrong geometry occurs in acquisition when there is miscommunication or wrong information between the 


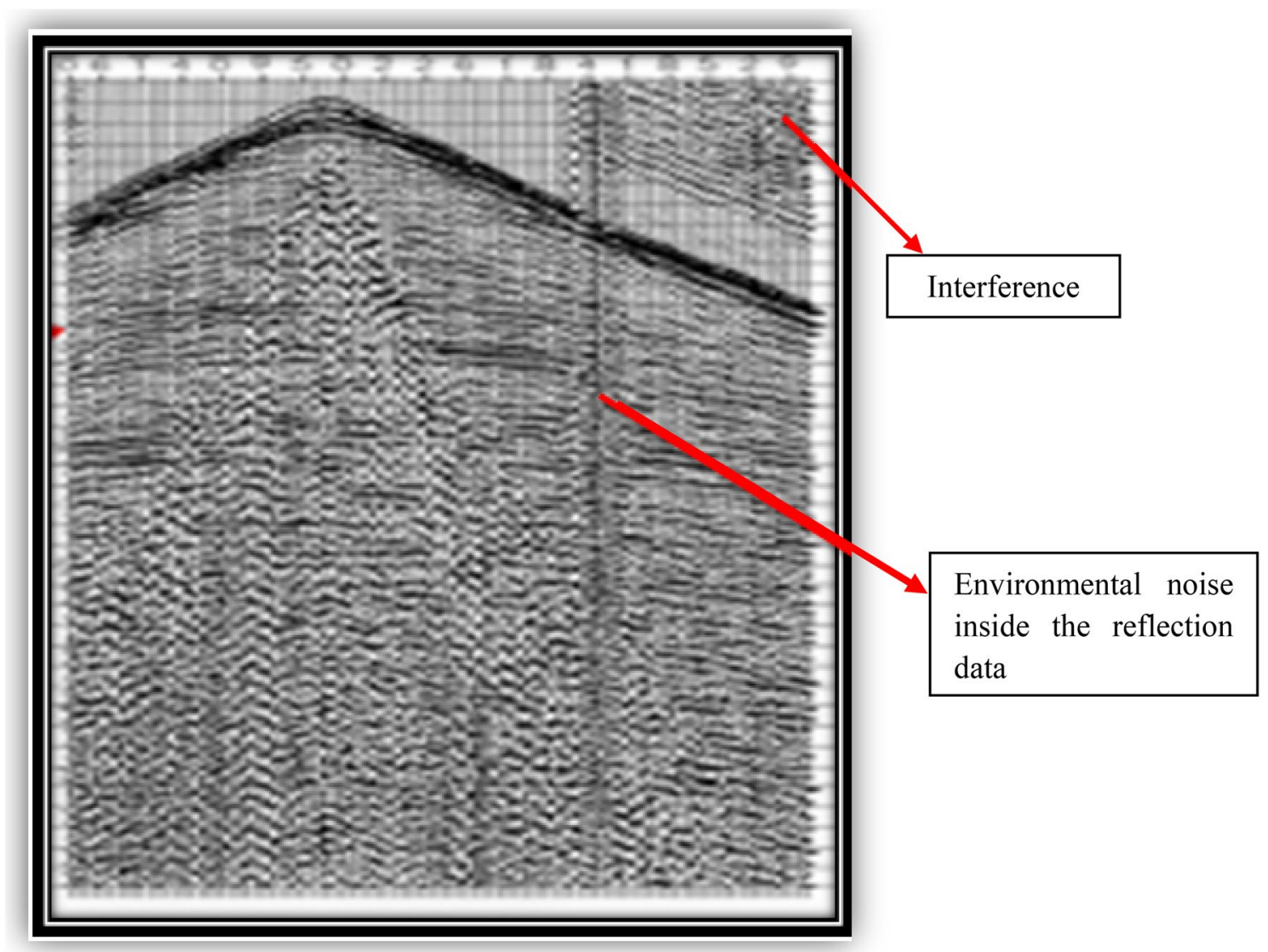

Fig. 11 Raw shot with interference and other environmental noise

observer at the platform and the shooter in the field. This wrong information or wrong detailing from the shooter will cause the observer to key in the wrong shot parameter (bin-in) into the Sercel acquisition workstation being used at the platform for the acquisition of that particular shot. This means that the acquired shot is having the information of another shot in the field. In this case, there will not be a linear move-out (LMO) during processing of that particular shot affected during processing.

\section{Caked or expired explosives}

This type of explosives will give rise to two major problems namely.

\section{Bad charge}

This is the inability of an explosive to detonate during shooting irrespective of the lead of the detonator being intact.

\section{Weak shot}

In this case, the explosive detonates, but produces such a weak energy that the signal almost gets attenuated before hitting the target layer. Apart from bad explosives, weak shots can as well result from poor tamping of SDH after loading of dynamites inside it. In this case, energy which is supposed to be directed downward escapes through the surface.

\section{Cap shot}

In this case, only the cap or explosive detonator shoots. The effect is almost similar to that of weak shot

\section{Poor and compromised supervision}

When a given depth is assigned to be drilled, it should be strictly adhered to. Within the Niger Delta, most acquisition SDHs are drilled to depths not less than $30 \mathrm{~m}$. This is to avoid the effects of the weathered zone or layers on the energy released. It is a well-established fact that sounds or energy travels faster in solid or more compacted

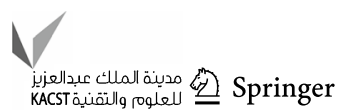






Fig. 12 A seismic shot with noise

medium than lesser compacted medium. Failure to drill to the specified depth will definitely affect the result. The speed of sound transmission will be reduced due to the weathered layer. Shallow SDHs can result to blow out which is not only a risk to the environment, but also to human lives most especially the shooting crew at the position. Another effect of not drilling to specifications is that of ground rolls which will be present in the acquired signal.

\section{Security and permit challenges}

The fact that properties (land) is owned by persons, organizations, etc., makes it very vital to get the permission of the owners before operation kicks off. Failure to reach a conclusive agreement with property owners will either delay or stall the operation. Therefore, the purpose for the project is defeated. Considering the cost of most acquisition equipment and some delicate materials usedexplosives, the presence of water tight security should not be over emphasized. Explosives in the wrong hands can be a national threat and should be guarded with all seriousness.

\section{Conclusion}

The geophysical challenges in land seismic data acquisition within the study area are quite enormous. It has been observed that poor environmental planning and weak policy implementation has caused the proliferation of nonseismic objects like buildings, etc., in areas strictly meant for seismic activities. This leads to the killing of most shot points, thereby affecting the expected fold of the prospect.

As a result of poor environmental planning and policy implementation, human activities are on the increase, thereby causing an increase in the rate at which environmental noise interferes with the acquired reflection data. Acquisition during cloudy and rainy conditions exposes both human lives and properties to high risk. It also affects the quality of data acquired by introducing noise from rain droplets into the data and as well causing line breaks due to electrostatic interference. It is of economic importance not to acquire under the rain or cloudy conditions as most shots acquired under this condition have a high tendency of being bad. It is most likely such bad shots need to be reacquired, hence increasing the cost of acquisition. 


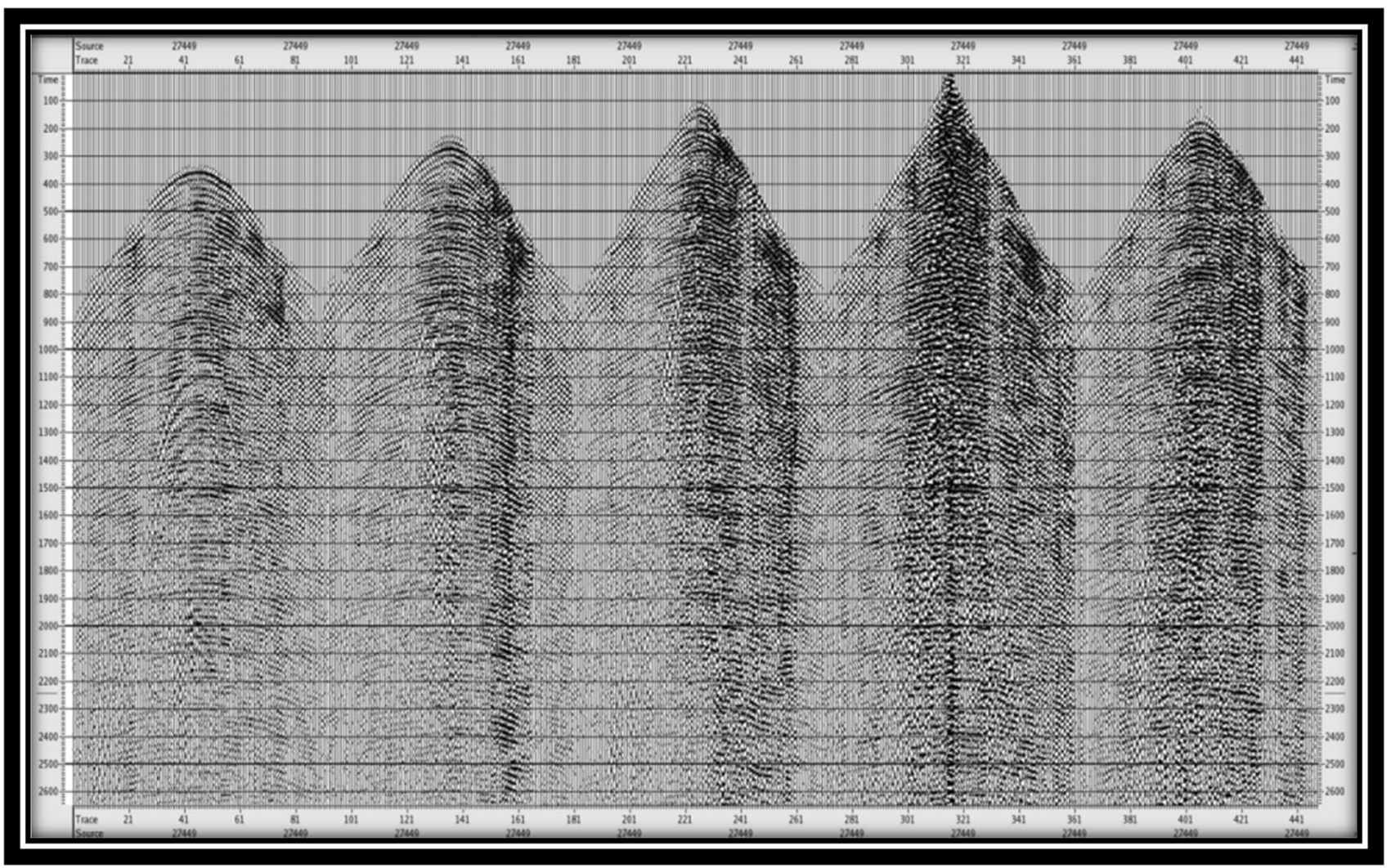

Fig. 13 Shot after noise attenuation

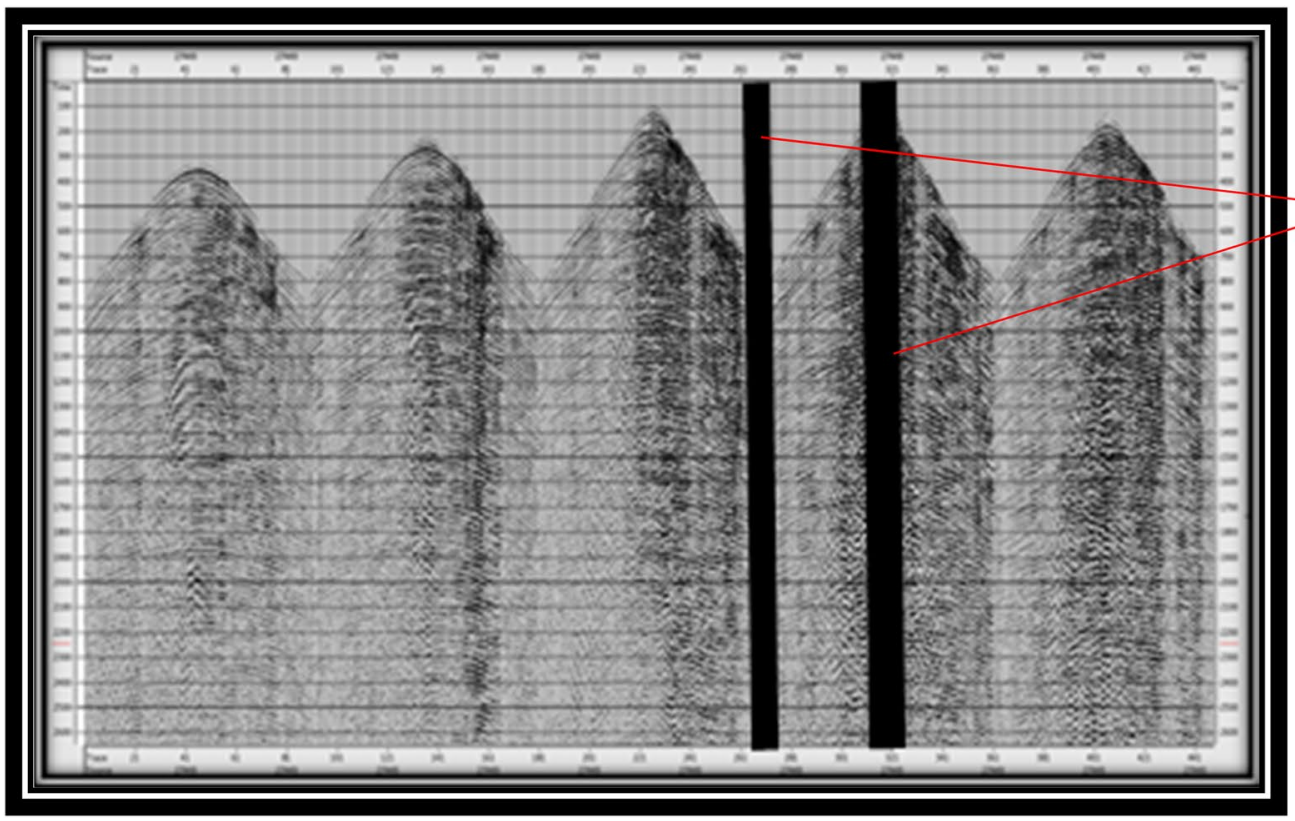

$\Longrightarrow \quad$ Line Breaks

Fig. 14 Shot with line break 


\section{Recommendations}

In order to minimize the geophysical challenges encountered in seismic data acquisition in Niger Delta, Nigeria, the following points should be strictly adhered to.

- Where Non-Seismic Objects (NSOs) prevent acquisition of some points where those points cannot be moved or "offset", infill shots that will possibly affect the bins to be sampled should be planted to compensate for fold drop and to meet the clients demand.

- In an area where noise cannot be avoided due to increase in human activities, it is advised that human activities should be monitored with keen interest as to know the period when these activities tend to be high or minimal. Acquisition is advised to be carried out at such times when activities are low to minimize interference. If also permitted, with adequate security and safety parameters put in place, night time could be the best time for acquisition within areas of high human activities.

- The idea of data acquisition during cloudy and rainy conditions should be strictly discouraged for the safety of lives and properties from lightning and thunder storms, reduction of noise from rain droplets entering the data and prevention of line breaks and electrostatic interference which will lead to reacquisition of already acquired shot. Routine check, maintenance, repair and replacement of all acquisition materials and equipment should be carried out to avoid bad shots like line breaks and cut charges resulting from faulty work material and equipment.

- Before a shot is taken, the observer at the platform should ensure that the information being passed to him from the field corresponds to that of the shot to be taken. To ensure this, there should be a repeat of information from the shooter at any particular shot point to ensure the right shot information is given. There should be a break for adequate rest for both the shooters in the field and the observers at the platform to ensure freshness and high sense of alertness to avoid keying in the wrong data as a result of fatigue.

- The magazine observer should ensure that all the explosives to be used in the operations are in the best condition to avoid weak shots, cap shots and even bad charges resulting from bad explosives.

- Proper and uncompromised supervision should be carried out by field quality control officers, to ensure that single deep holes $(\mathrm{SDH})$ are drilled to specifications and that the loading of explosives is properly done, with holes well tamped to avoid escape of energy from the ground.

- The community affairs and security departments should ensure that there is proper permitting and adequate secu- rity on ground to prevent communal and irate youth disturbances which could hamper or stall the acquisition operations.

Funding Funded by BGP/CNPC Int'l Nigeria LTD (Crew 8619).

Open Access This article is licensed under a Creative Commons Attribution 4.0 International License, which permits use, sharing, adaptation, distribution and reproduction in any medium or format, as long as you give appropriate credit to the original author(s) and the source, provide a link to the Creative Commons licence, and indicate if changes were made. The images or other third party material in this article are included in the article's Creative Commons licence, unless indicated otherwise in a credit line to the material. If material is not included in the article's Creative Commons licence and your intended use is not permitted by statutory regulation or exceeds the permitted use, you will need to obtain permission directly from the copyright holder. To view a copy of this licence, visit http://creativecommons .org/licenses/by/4.0/.

\section{References}

Agoha CC, Opara AI, Okereke CN, Onwubuariri CN, Emberga TT, Inyang GE, Ugwuegbu IE, Chilaka JC (2015) Weathered layer determination and its effects on engineering structures: case study of parts of the Niger delta. World Environ Eng 3(2):40-51

Doust H (1990) Petroleum geology of the Niger Delta. Geol Soc, London, Special Publications 50(1):365. https://doi.org/10.1144/GSL. SP.1990.050.01.21

Doust H, Omatsola E (1990) Niger delta. In: Edwards JD, Santogrossi PA (eds) Divergent/passive margin basins. AAPG Memoir 48. American Association of Petroleum Geologists, Tulsa, pp 239-248

Ejedawe JE (1981) Patterns of incidence of oil reserves in Niger Delta Basin. American Association of Petroleum Geologists (AAPG), vol. 65

Hospers J (1965) Gravity field and structure of the Niger delta, Nigeria, West Africa. Geol Soc Am Bull 76:407-422

Kaplan A, Lusser CU, Norton IO (1994) Tectonic map of the world, panel 10: Tulsa. American Association of Petroleum Geologists, scale 1: $10,000,000$

Klett TR, Ahlbrandt TS, Schmoker JW, Dolton JL (1997) Ranking of the world's oil and gas provinces by known petroleum volumes. U.S. Geological Survey Open-file Report-97-463, CD-ROM

Kulke H (1995) Nigeria. In: Kulke H (ed) Regional petroleum geology of the world. Part II: Africa, America, Australia and Antarctica. Borntraeger, Berlin, Gebriider, pp 143-172

Warebi GB, Tonye DP (2018) Lessons learnt from the 2012 flood disaster: implications for post-flood building design and construction in Yenagoa, Nigeria. Civil Eng Archit 6(3):171-180. https://doi. org/10.13189/cea.2018.060307

Weber KJ, Daukoru EM (1975) Petroleum Geology of the Niger Delta. In: Proceedings of the ninth World Petroleum Congress, vol 2. Geology Applied Science Publishers, Ltd, London

Publisher's Note Springer Nature remains neutral with regard to jurisdictional claims in published maps and institutional affiliations. 